\title{
COMPARTIMENTAÇÃO DA PAISAGEM EM BASES GEOSSISTÊMICAS DO ALTO CURSO DO RIO CANHOTO, PLANALTO DA BORBOREMA, NORDESTE DO BRASIL
}

\section{LANDSCAPE COMPARTMENTS ON GEOSYSTEMIC BASIS IN THE UPPER REACH OF THE CANHOTO RIVER, BORBOREMA HIGHLANDS, NORTHEAST OF BRAZIL}

\author{
Évio Marcos Lima', Antonio Carlos Barros Corrêa ${ }^{1}$ \\ ${ }^{1}$ Universidade Federal de Pernambuco (UFPE), Pernambuco, PE, Brasil
}

Correspondência para: Évio Marcos Lima (eviolima1@gmail.com)

doi: 10.12957/geouerj.2019.38012

Recebido em: 26 out. 2018 | Aceito em: 17 set. 2019

\section{RESUMO}

O termo paisagem possui muitas aplicações e significados em geografia, constituindo um conceito-chave para essa ciência. Neste trabalho foi proposta uma compartimentação síntese para as paisagens do alto curso da bacia do Rio Canhoto, Pernambuco, no domínio morfoestrutural do Planalto da Borborema. O enfoque da investigação busca contribuir com as discussões sobre a análise e evolução das paisagens semiáridas brasileiras. A metodologia aplicada baseou-se em uma adaptação da cartografia geossistêmica, ao contexto fisiográfico do Nordeste oriental do Brasil. Foram identificados, cinco sistemas de paisagens que apresentam dinamismo particular e respondem a controles próprios. Observou-se que a variação dos elementos estruturadores desses sistemas corresponde a mudanças nos atributos ambientais, resultando na formação de paisagens de exceção no contexto regional semiárido. Outrossim, observou-se que a morfologia das paisagens em questão também reflete o acúmulo em superfície das transformações paleoclimáticas ocorridas ao longo do Holoceno. Conclui-se que a metodologia de modelagem cartográfica geossistêmica representa uma importante ferramenta ao trabalho de descrição da paisagem para fins geomorfológicos, constituindo também um mecanismo eficiente de análise ambiental.

Palavras-chave: Cartografia geossistêmica, Modelagem, Compartimentação, Síntese Paisagística, Nordeste do Brasil.

\begin{abstract}
The term landscape has a large number of applications and meanings in geography, constituting a key concept for this science. In this work a compartmentalization synthesis was proposed for the landscapes of the upper reaches of the Canhoto River watershed, Pernambuco, in the morphostructural domain of the Borborema Highlands. The research focus seeks to contribute to the discussions concerning the analysis and evolution of the Brazilian semi-arid landscapes. The applied methodology was based on an adaptation of geosystemic cartography, to the physiographic context of eastern Northeast of Brazil. Five landscapes systems were identified that show particular dynamism and respond to their own controls. It was observed that the variation of the structural elements of these systems corresponds to changes in the environmental attributes, resulting in the formation of exceptional landscapes within the semi-arid regional context. Also, it was observed that the morphology of the landscapes in question also reflects the surface accumulation of paleoclimatic transformations occurring along the Holocene. It is concluded that the methodology of geosystemic cartographic modeling represents an important tool for describing the landscape for geomorphological purposes, constituting also an efficient mechanism of environmental analysis.
\end{abstract}

Keywords: Geosystemic cartography, Modeling, Compartmentation, Landscape Synthesis, Northeast of Brazil.

\section{INTRODUÇÃO}


O conceito de Paisagem pode resultar em um sem número de definições e/ou sinônimos dentro das mais variadas condutas analíticas. Na ótica da geografia, se trata de um conceito-chave fundamental às discussões desta ciência (AB'SABER, 2003), sejam aplicadas aos elementos físico-naturais ou às manifestações sociais e culturais. Dentre os diversos campos de conhecimento que integram a geografia física, a geomorfologia é a ciência que mais recorre ao uso dessa epígrafe, chegando a instituir a paisagem como seu objeto de estudo. Ao longo do seu desenvolvimento, diversas ferramentas concorrem para auxiliar a compreensão da paisagem sob o prisma da geomorfologia; uma dessas é a proposta do geossistema (SOCHAVA, 1963) com forte difusão inicial na geografia russo/soviética, havendo posteriormente alcançado escolas geográficas da Europa ocidental e até o Brasil (CHRISTOFOLETTI, 1999).

Segundo Christofoletti (1999), a primeira síntese natural a ganhar força naquele país, foi descrita no início do século XX por Dokoutchaev (1843-1903), caracterizando o "Complexo Natural Territorial" como um recorte espacial onde os fatos da natureza interagem em codependência. O geógrafo francês Georges Bertrannd irá promover uma definição particular para o conceito de geossistemas, arraigado nas definições dos sistemas naturais propostos por Tricart e Cailleux (1956), de forma que, sua concepção não engloba o cerne fundamental do conceito soviético, de que os geossistemas não possuem uma definição territorial pré-concebida, podendo fazer referência desde o planeta Terra até uma mancha de solo sobre leito rochoso com vegetação rasteira (CAVALCANTI, 2013). Contudo, os trabalhos de Bertrannd irão desenvolver excelsa influência no mundo acadêmico brasileiro, ao passo que, durante muitos anos no século XX haverá uma confusão entre os conceitos e sua abordagem na geografia do Brasil (CORREA, 2010). Os esforços desta correção ainda são necessários, sobretudo, pelas reverberações dos trabalhos iniciais dos geógrafos franceses aqui no país (CAVALCANTI, 2013).

A proposta sistêmica, quando atrelada ao estudo das paisagens se beneficiou do desenvolvimento do conceito do geossistema (SOCHAVA, 1963), sobretudo conquanto a paisagem for abordada como um complexo físico, espacialmente discernível, a partir da organização hierárquica e troca de fluxos entre seus elementos componentes. Seguindo com o raciocínio, Cavalcanti (2013, p. 41) discorre sobre o conceito de paisagem afirmando que esta, se trata de 
uma área específica, homogênea em sua origem e história de desenvolvimento, com o mesmo fundamento geológico, o mesmo tipo de relevo, o clima geral, uma combinação uniforme de condições hidrotermais, solo, biocenoses e conjunto lógico de partes morfológicas - fácies e tratos.

Com efeito, as bases para uma compreensão "sistêmica" da integração de elementos estruturadores, na análise de uma paisagem já estavam presentes desde o século XIX, (CAVALCANTI, 2014). 0 mesmo autor (CAVALCANTI, 2014, pág. 19), ainda afirma que

as paisagens acumulam a história dos processos tectônicos, geomrfológicos, climáticos, hidrológicos, biogeográficos e culturais, mas são, antes de tudo, entidades da ordem do presente, pois constituem o resultado geoecológico e visível da interação de elementos e processos naturais e culturais.

Enquanto agente partícipe da evolução das paisagens, o tempo, pode ser "recortado", a fim de que se compreenda o estado em que se encontra um pedaço do espaço em um determinado momento. No caso deste trabalho, o momento escolhido foi o presente, compreendido também como o somatório dos tempos passados, refletidos sobre a organização espacial (CORREAA, 2007).

Nessa linha de raciocínio, em compasso com as definições de "sínteses paisagísticas", propostas por Ab'saber (2003) para domínios de paisagens, tem-se a perspectiva de um desses domínios, o semiárido, como síntese regional, caracterizado por uma zona de precipitação concentrada e imposição da denudação sobre a pedogênese e vegetação xerófila, salvo condições de imposição antropológica.

Por outro lado, há ainda, como domínio partícipe da região Nordeste, dado pelo mesmo autor, a formação dos mares de morros, caracterizados pela alta temperatura e recorrência de precipitação bem distribuída com índices pareados ao ambiente tropical úmido, onde haverá presença da floresta ombrófila, a qual, será atribuída a alcunha de "Mata Atlântica", a qual, com a interferência dos processos econômicos de transformação dos espaços, tem percebido a presença de uma gama de espécies exóticas à região, mas bem adaptadas ao clima correlato, impondo evidente dualidade com a zona semiárida (AB'SABER, 2003).

A escolha em particular deste trecho da bacia do Rio Canhoto, surgiu em decorrência da sua localização em uma área de transição ambiental que, segundo a perspectiva de Ab'Saber (2003), consiste em uma 
região cujas características físicas e ambientais sofrem uma variação dentro de um determinado espaço; esse trânsito, fica marcado pelas variações paisagísticas perceptíveis no recorte analisado.

Aliada a um arcabouço gráfico, Cavalcanti (2013) propôs uma modelagem para um geossistema de ambiente semiárido em Pernambuco. Posteriormente, o mesmo autor (2014) apresentou uma proposta de modelagem cartográfica aplicada aos geossistemas.

Em suma, a teoria do geossistema, largamente aplicada no contexto da geografia Russa/Soviética, trata a paisagem como uma área natural formada pela interação funcional de tratos, que representam subcontextos físico/químico/biológicos de um sistema físico, tais como a relação entre a geologia, a pedologia e a formação vegetal de uma superfície. Esses podem ainda ser sintetizados como a atuação de fatores bioclimáticos sobre uma morfoestrutura, em mesoescala (CAVALCANTI, et. al. 2016) ou, segundo afirmou Solnetsev (1967, apud CAVALCANTI, et. al. 2016, p.8) “uma área geneticamente homogênea, com uma repetição regular de combinações inter-relacionadas da estrutura geológica, formas de relevo, águas superficiais e subterrâneas, microclimas, solos, fito e zoocenoses". Com base nesta perspectiva metodológica este trabalho propõe construir uma síntese paisagística para o alto curso do Rio Canhoto, sobre o setor oriental do Planalto da Borborema.

Essa reconstrução dos encaminhamentos teóricos é fundamental quando se propõe síntese analítica de uma paisagem, metodologicamente consistente, sobretudo quando o recorte espacial analisado abriga uma variação nos controles dinâmicos que ocasiona uma transmutação das formas e componentes estruturadores. A área de estudo (FIGURA 1), está situada sobre uma faixa transitória entre dois arranjos ambientais fortemente relacionados à configuração topográfica e aos condicionantes morfoestruturais, que atuam orientando a dissipação da energia participante nos sistemas físicos presentes. 


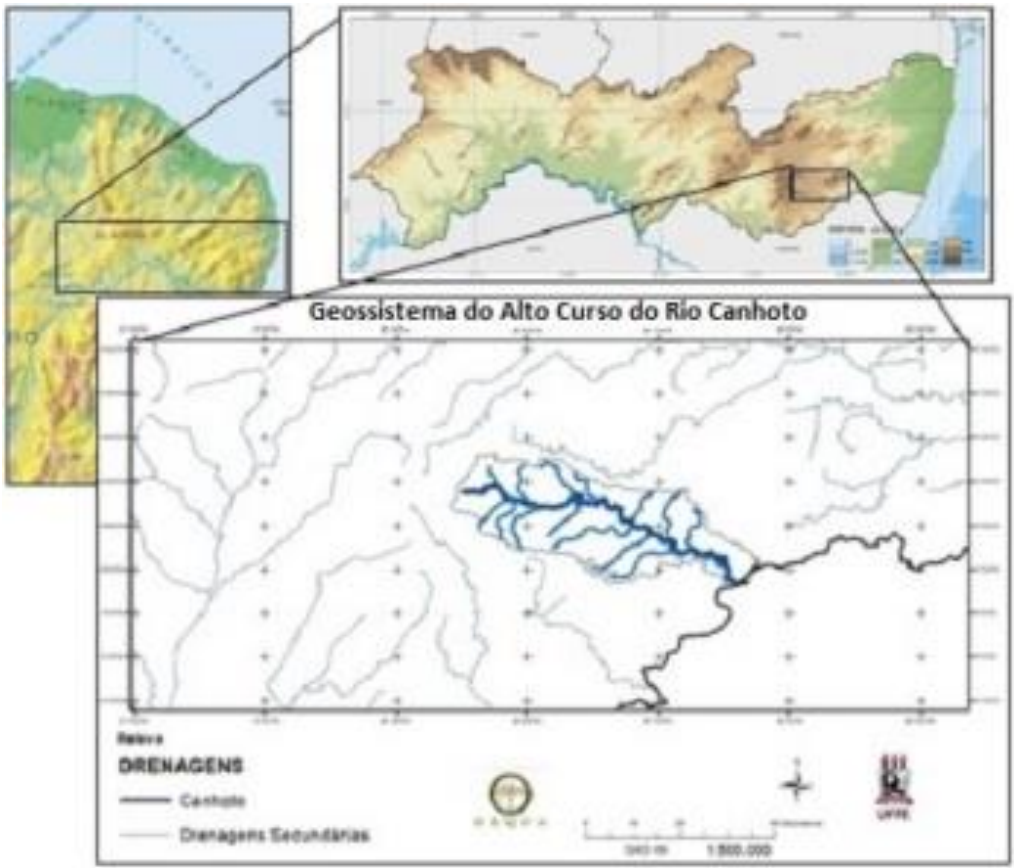

Figura 1. Localização da área de estudos Fonte: Elaborado pelos autores.

Desta forma, este trabalho buscou promover uma síntese das paisagens da área de estudo com o estabelecimento da relação processo-forma, sempre atentando às suas diferentes escalas de atuação. A área em apreço está situada geologicamente sobre o Terreno PE/AL, descrita como uma faixa alóctone granítico-migmatítica. Esta unidade compreende suítes de leucogranitóides metaplutônicos ao norte; gnaisses e leucórsios do Complexo Cabrobó, distribuídos em faixas ao sul, leste e norte; suíte ortognaisica metaplutônica em uma pequena faixa ao Norte; e um conjunto de metagranitóides indiscrimidados do complexo Belém de São Francisco em faixas a oeste, centro e sudeste (AZAMBUJA, 2007) (FIGURA 2).

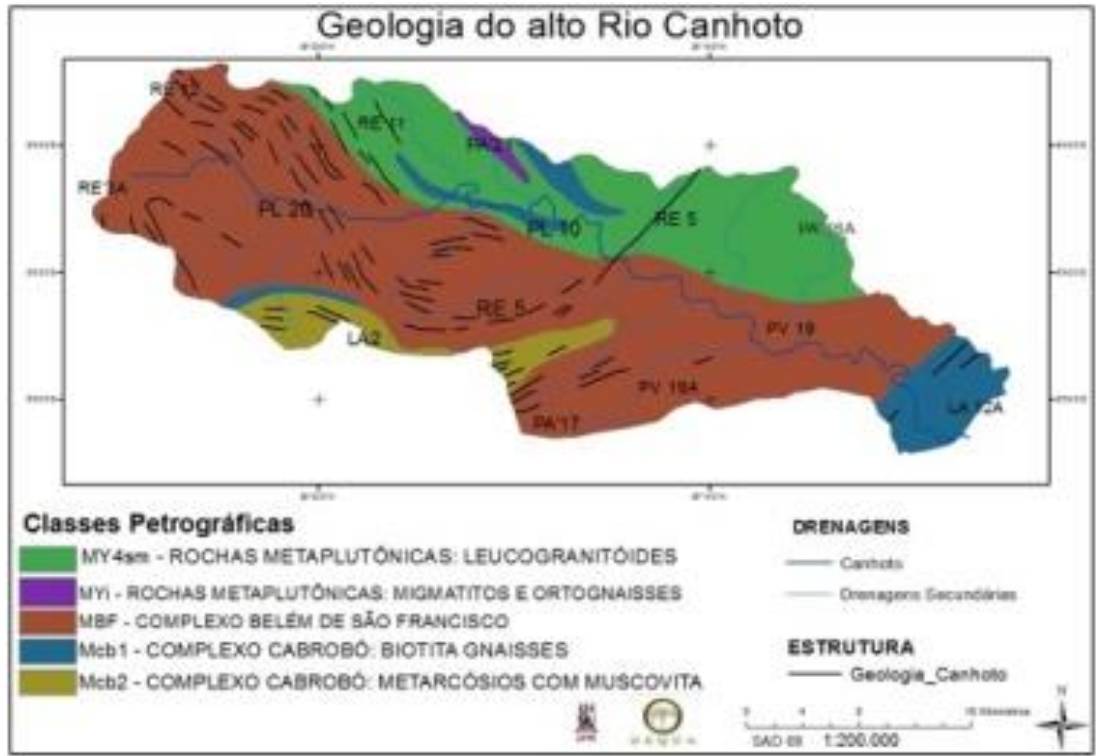

Figura 2. Geologia da bacia do rio canhoto Fonte: Elaborado pelos autores. 
Estruturalmente, uma série de alinhamentos, ora no sentido NE/SO, ora dispostos paralelamente desde a faixa central até às superfícies mais elevadas na porção NO/SE podem ter contribuído para a dispersão dos arranjos plutônicos bem como para o prolongamento dos variáveis graus de metamorfismo evidenciados nos componentes petrográficos na área. Os sistemas sinóticos mais relevantes que atuam na área são a Zona de Convergência Inter Tropical - ZCIT e a Alta Subtropical do Atlântico Sul-ASAS (AZAMBUJA, 2007), que por sinal, constituem dois dos principais sistemas atuantes no NE do Brasil (MOLION \& BERNARDO, 2002). De acordo com Lima (2014) a atuação mais expressiva desses sistemas se dá entre os meses de janeiro a junho. Sendo, os seis últimos meses do ano, o período mais seco da região. Esta dinâmica está condicionada ainda à presença de um Vórtice Ciclônico de Altos Níveis - VCAN -, este fenômeno é responsável por confinar a concentração de umidade às suas margens e, devido o contato do continente com o Oceano atlântico, às proximidades com o litoral. No caso da bacia do rio Canhoto, sua zona terminal resta, dependendo da intensidade de atuação do VCAN, em contato com as bandas de umidade que penetram o continente, vindas de Leste-Sudeste, também impulsionadas pelos alísios.

\section{Objetivo}

O principal objetivo deste trabalho foi propor uma compartimentação sintética das paisagens sobre uma zona de transição ambiental situada no sudeste do estado de Pernambuco, tendo por objeto de análise o alto curso do rio Canhoto, seguindo o modelo de delimitação proposto por Cavalcanti (2014).

Para estes fins fez-se necessário inicialmente identificar a influência estrutural sobre a distribuição das unidades geomórficas, seguida do diagnóstico das relações estrutura-clima expressas na morfologia da paisagem. Neste sentido compreende-se a compartimentação geomorfológica como o saldo resultante da ação de agentes endógenos e exógenos na área da bacia, com foco para as interações rocha x relevo, estrutura x relevo e clima x coberturas superficiais no setor leste do Planalto da Borborema.

As descrições acima enunciadas ensejaram a elaboração de um mapeamento das características ambientais da área, sob a forma de uma síntese da paisagem de conotação genética; constituindo ainda 
uma modelagem em área de transição entre os componentes fisiográficos do litoral úmido e interior semiárido do Nordeste oriental.

\section{PROCEDIMENTOS METODOLÓGICOS}

A primeira etapa prática do trabalho constituiu-se em um levantamento de campo, no qual foi percorrida toda a área de estudo ao longo de duas visitas; a primeira em agosto de 2017 e a segunda em novembro do mesmo ano. Nestas oportunidades foram visitados os complexos de paisagens que mais tarde resultariam na compartimentação em bases geossistêmicas. As visitas permitiram estabelecer ajustes no mapeamento prévio dos compartimentos geomorfológicos, identificação das formas de cobertura da terra, além da observação in situ dos processos de superfície terrestre em operação na região. Nesta etapa também foram identificadas as encostas com e sem cobertura coluvial, além de levantados perfis pedológicos e sua relação com a estruturação das superfícies, com o objetivo de compreender o papel das coberturas superficiais, residuais e remobilizadas, na gênese das formas de relevo.

Em gabinete, os dados coletados em campo foram acrescentados à metodologia proposta de elaboração de produtos gráficos baseados na classificação assistida de imagens de sensoriamento remoto, por meio da utilização do software ARCGIS 10.1. Por fim, foi possível manipular dados matemáticos a fim de construir produtos que ilustram graficamente as situações identificadas nas áreas.

A construção dos mapas temáticos seguiu a orientação metodológica proposta por Cavalcante (2014), voltada para a elaboração de cartas geossistêmicas. Em função da escala de representação dos fatos geomorfológicos encontrados na área de estudo optou-se por aplicar a esta análise o primeiro patamar da classificação de paisagem, ou seja, a unidade denominada de "sítios". Para este nível de classificação foram identificadas as formas do relevo - segmentos ordenados segundo diferentes escalas de abordagem e sua correlação com o substrato - definidos como o resultado da interação entre geologia e ambiente, podendo abarcar desde formas estruturadas pela exposição da rocha sã até aquelas recobertas por espesso manto de intemperismo, ou sedimentos remobilizados a curta distância (coberturas alúviocoluviais). 
Parte desta classificação seguiu a orientação do trabalho realizado por Lima (2014) onde foi definida a compartimentação da geomorfologia do município de Garanhuns, sendo este, um dos municípios que abrange maior território dentro da bacia. O processo de confecção dos produtos gráficos foi realizado nas seguintes etapas; a primeira destas consiste na obtenção da base de dados matemáticos, que foi conseguida junto à Empresa Brasileira de Pesquisa Agropecuária - EMBRAPA. Após essa etapa foi utilizada uma demarcação seguindo as curvas de nível locais para caracterização das zonas-limites da bacia de drenagem do Rio Canhoto.

Uma vez delimitada a área de estudos, foram definidas as formas do relevo observadas segundo uma classificação morfoestrutural, tal configuração foi definida seguindo orientação da União Geográfica Internacional - UGI -, de acordo com o tratado de mapeamento geomorfológico definido por Demek (1972). A base de dados utilizada foi a do tipo .TIFF, obtida junto à National Aeronaltics and Space Administration - NASA, sendo trabalhada em âmbito SIG com o software ArcGis 10.1, além dos softwares de código aberto QuantumGIS e Google Earth.

A classificação do substrato se baseou na estrutura e cobertura da superfície como base para o entendimento desta relação, assim, foram investigadas as ocorrências litológicas da região, com informações obtidas junto à Companhia de Pesquisa em Recursos Minerais - CPRM - bem como, através dos dados disponibilizados pela Empresa Brasileira de Pesquisa Agropecuária - EMBRAPA - para arguições sobre a cobertura pedológica além, evidentemente, da observação de campo.

A estrutura geológica percebida inclui rochas cristalinas plutônicas sendo dividas de acordo com nível de acidez dos indivíduos ("rochas ácidas" com mais de 65\% de sílica; "rochas neutras" ou "intermédias", com 65 a 52\% de sílica; e "rochas básicas", com 52 a 49\% de sílica), sendo estes dados já conhecidos de acordo com cada tipo de rocha identificado junto CPRM. Enquanto a cobertura foi considerada segundo o aspecto pedológico com inferências que alcançaram desde coberturas arenosas até solos ricos em argila, além das coberturas tomadas por capeamentos sedimentares, sendo classificados de acordo com sua profundidade mensurável. 
Por fim, a síntese da paisagem teve seus paradigmas de constituição elencados por Cavalcanti (2014), a saber: "Potencial natural" e "apropriação cultural", sendo distinguidos da seguinte forma:

Potencial natural - componentes estruturais e processos tectônicos correlatos, associados aos processos climáticos e a reverberação desta associação no desenvolvimento da superfície e na caracterização das redes de drenagens. Perceptivelmente este potencial está exposto no mapa que explicita a relação entre o relevo e o substrato.

Apropriação Cultural - correspondendo à forma de uso e ocupação da superfície, bem como às transformações e implicações resultantes desse processo. A apropriação cultural pode ser observada no mapa que expõe os estados da superfície.

A análise final buscou coadunar as informações a fim de construir o panorama paisagístico sintetizado em seis seguimentos, a saber:

- Agreste

- Pântano Pluviogênico

- Brejo

- Rampa Transicional

- Tropical

As formas do relevo foram definidas em:

- Cimeira Somital Bem Drenada.

- Pedimentos Elevados, Inclinados, Pouco Dissecados.

- Pedimento Pouco Dissecado Com Estagnação de Água (ainda que periódica).

- Superfície Metamórfica com Cristas de Dissecação (Proeminentes ou em formação)

- Vertentes Íngremes e Drenadas.

- Vertentes Rebaixadas Bem Drenadas Com Incisões Profundas. 


\section{RESULTADOS}

A síntese das paisagens presentes na área de estudos foi pautada na compilação dos dados armazenados e correção dos mesmos a partir das visitas de campo. Desta forma, os resultados das análises serão expostos por etapas, com a conclusão dessas informações sendo esmiuçadas adiante.

Dentro de um enfoque geossistêmico, de acordo com a proposição destacada por Sochava (1976), as seis classificações morfológicas realizadas podem ser assinaladas como "fácies", com base em uma escala de classificação das relações físico-químicas possíveis. Assim, serão apresentadas as características aferidas a cada fácie, sobrepondo sempre que possível, o contexto processual dos ambientes aos quais se referem.

A tabela (tabela 1) a seguir, estabelece a relação entre o relevo e o substrato, definindo assim um esquema dos sítios paisagístico em bases geossistêmicas da região estudada. É possível observar que a presença das litologias metamórficas está associada ao relevo mais acidentado, sendo clara a relação da transformação do substrato geológico em face dos esforços de sobre-elevação tectônica dos blocos em superfície. Estas antigas faixas móveis, agora em contexto intraplaca, se distribuem ao longo de planos de fraqueza regionais (MAIA, 2012), ao longo dos quais, podem se ajustar as drenagens. Esses ainda podem atuar como áreas preferenciais para a orientação e direcionamento dos fluxos superficiais, bem como, por sua fragilidade ao ajuste erosivo dos canais, orientar a incisão.

\begin{tabular}{c|c|c|c|c|c|c|c|c|c|c|}
\hline \multirow{2}{*}{ Relevo } & \multicolumn{4}{|c|}{ Rocha } & \multicolumn{5}{c|}{ Cobertura } \\
\cline { 2 - 11 } & \multicolumn{2}{|c|}{ İgnea } & \multicolumn{2}{c|}{ Metamórfica } & $\begin{array}{c}\text { Solo Arenoso a } \\
\text { Franco Arenoso }\end{array}$ & $\begin{array}{c}\text { Solo Médio a } \\
\text { Argiloso }\end{array}$ & \multicolumn{2}{c|}{ Sedimentar } \\
\cline { 2 - 11 } & Ácida & Básica & Ácida & Básica & Regolitico & Não Rego. & C/ Casc. & S/ Casc. & Delgado & Profunda \\
\hline $\begin{array}{c}\text { Cimeira somital bem } \\
\text { drenada }\end{array}$ & $\mathrm{X}$ & & $\mathrm{X}$ & & & & $\mathrm{X}$ & & & $\mathrm{X}$ \\
\hline $\begin{array}{c}\text { Pedimentos elevados, } \\
\text { inclinados, pouco } \\
\text { dissecados }\end{array}$ & $\mathrm{X}$ & & $\mathrm{X}$ & & $\mathrm{X}$ & $\mathrm{X}$ & & & $\mathrm{X}$ & \\
\hline $\begin{array}{c}\text { Pedimento pouco } \\
\text { dissecado, com } \\
\text { estagnação de água }\end{array}$ & $\mathrm{X}$ & & $\mathrm{X}$ & $\mathrm{X}$ & $\mathrm{X}$ & $\mathrm{X}$ & & & $\mathrm{X}$ & \\
\hline $\begin{array}{c}\text { Zona de Metamorfismo e } \\
\text { Formção de Cristas }\end{array}$ & $\mathrm{X}$ & & $\mathrm{X}$ & & $\mathrm{X}$ & & $\mathrm{X}$ & & $\mathrm{X}$ & \\
\hline $\begin{array}{c}\text { Vertente ingreme muito } \\
\text { dissecada }\end{array}$ & $\mathrm{X}$ & & $\mathrm{X}$ & & & $\mathrm{X}$ & $\mathrm{X}$ & & $\mathrm{X}$ & \\
\hline $\begin{array}{c}\text { Vertente rebaixada com } \\
\text { incisões profunda }\end{array}$ & $\mathrm{X}$ & & $\mathrm{X}$ & $\mathrm{X}$ & & & $\mathrm{X}$ & $\mathrm{X}$ & & $\mathrm{X}$ \\
\hline
\end{tabular}

Tabela 1. Atribuição dos sítios paisagísticos da bacia do Rio Canhoto. Fonte: Elaborada pelos autores 
Os sítios paisagísticos aqui analisados interagem também com as condições ambientais do geossistema. A ausência de rochas sedimentares, permeáveis, contribui para a relação entre a imposição orográfica sobre o condicionamento da pluviosidade e o desenvolvimento de um relevo dissecado que preserva as marcas das variações climáticas holocênicas. A oeste da bacia, o clima semiárido dificulta a evolução pedogenética, assim são verificados solos rasos, as vezes recobertos por um capeamento sedimentar incipiente e, não raro, o material regolítico aflora diretamente à superfície.

A exceção a estes cenários ocorre nos setores mais expostos à penetração da umidade aportada pelos alísios de sudeste. Desta forma, os compartimentos "Cimeira Somital", "Zona de metamorfismo" e "Vertente Rebaixada" podem desenvolver uma mancha edáfica mais espessa, sendo, as duas primeiras áreas, zonas de expansão contemporânea do ambiente semiárido. A incomum presença de regolitos mais profundos, podem levar esses setores a serem classificados como “Áreas de Exceção” conforme a acepção de Ab'saber (AB'SABER, 2003), ao passo que o setor denominado de "Vertente Rebaixada", jaz sob condições constantes de ambiente tropical-úmido, algo equivalente ao "Domínio Tropical Atlântico" (AB'SABER, 2003).

\section{Síntese Paisagística}

A síntese ora apresentada (FIGURA 3) resulta da sobreposição de informações ambientais tais como essas se apresentam na paisagem hodierna, sendo as unidades definidas o reflexo dos resultados de cada composição interativa, assumindo-se a priori que a paisagem é um ente dinâmico, logo o que pode ser convertido em imagem não é nada mais que um "retrato" instantâneo. 


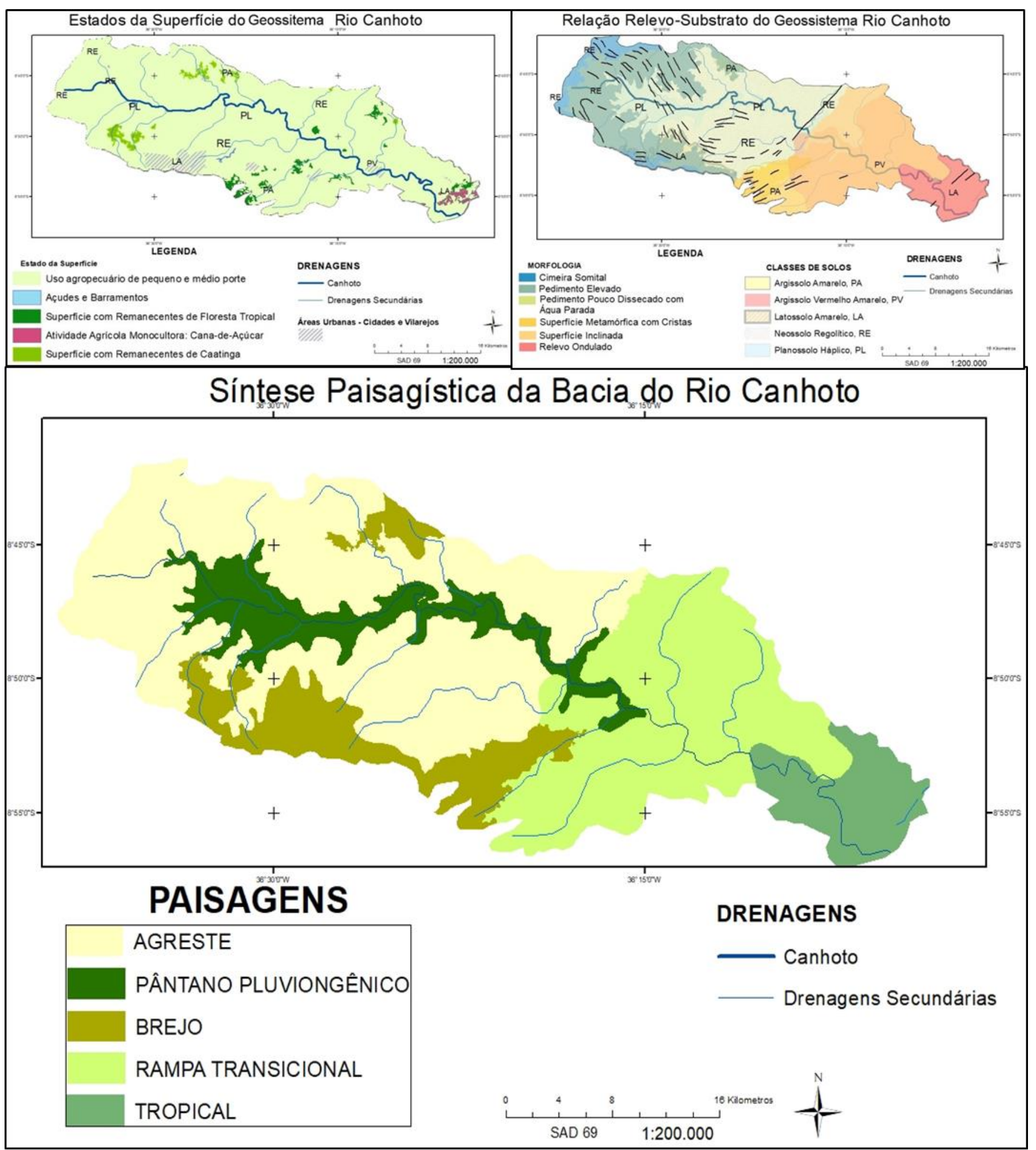

Figura 3. Relação Relevo-substrato-estado da superfície da Bacia do Rio Canhoto. Fonte: Elaborado por Autor

Nos trechos considerados como "Agreste", notavelmente mais presentes na faixa ao noroeste e centro da área de estudo, a exposição das coberturas superficiais revela a concentração de argila em horizontes subsuperficiais dos mantos de alteração, sendo essas, gradualmente eliminadas do sistema pedológico à 
medida que se aumenta o gradiente de semiaridez. Tal cenário de variação textural das coberturas residuais in situ sugere que a região pode estar atravessando um momento menos úmido, favorecendo a formação de solos arenosos, progressivamente mais delgados a noroeste, em consequência da remoção dos finos (Silte/Argila) sob condições de reduzido intemperismo geoquímico atual.

As formações vegetais que compõem a de cobertura da terra têm relação com as formas de usos correntes da superfície, onde predominam gramíneas relativas para o pastoreio, além da espécie arbórea exótica Prosopis Juliflora, "Algaroba", típica dos desertos peruanos. A secura generalizada desta unidade de paisagem, entretanto, não impede a formação de marcas profundas de dissecação pluvial e drenagens acompanhando a inclinação das vertentes. 0 escalonamento do relevo em patamares, expõe suaves inclinações em forma de rampas às cotas menos elevadas da bacia nos setores leste e sudeste, onde, a penetração da umidade enseja o desenvolvimento de linhas de incisões tão profundas quanto as coberturas pedológicas permitem, sendo, este processo, intensificado pela ação antrópica, sobretudo pela pecuária de pequeno porte (Figura 4).

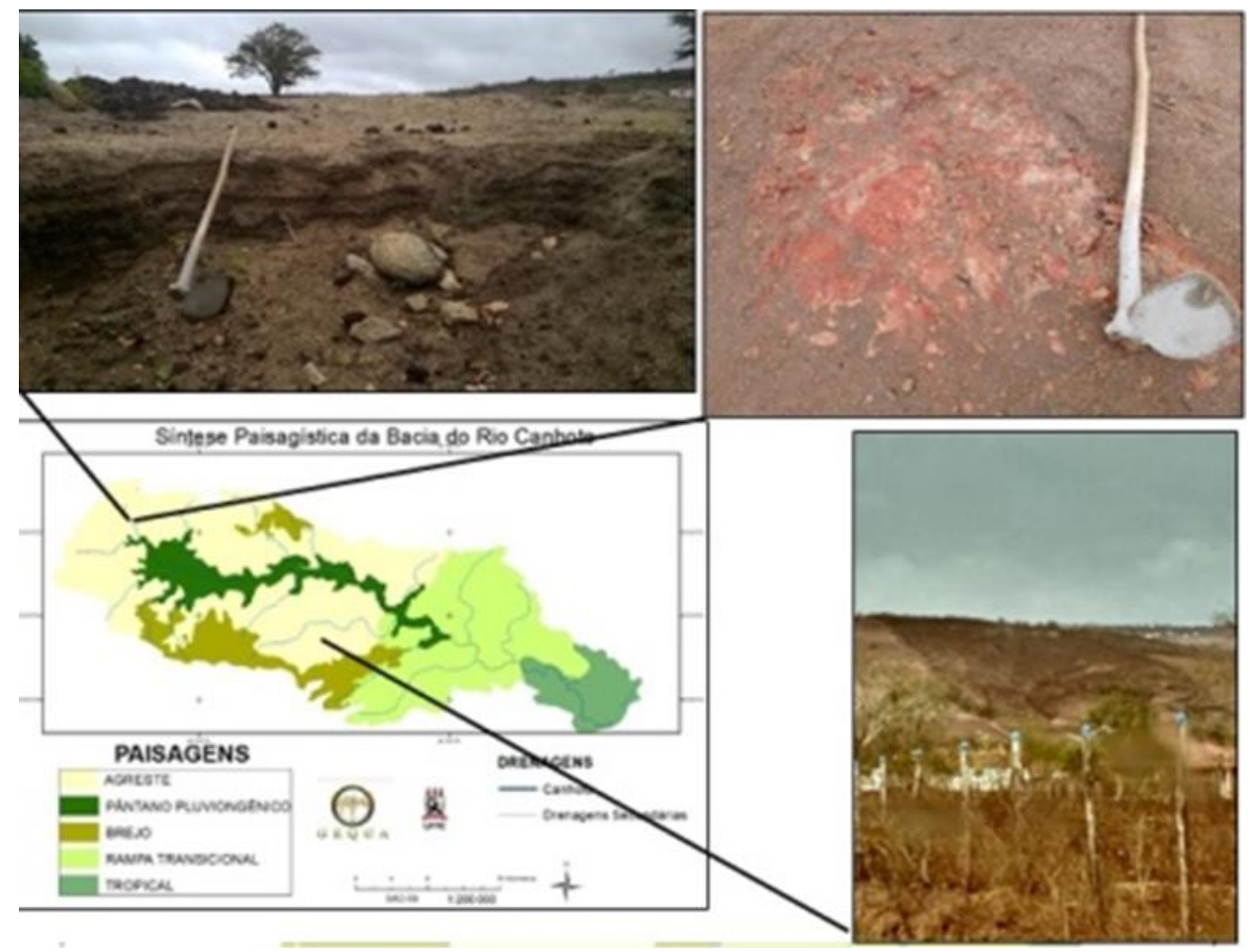

Figura 4. Compartimento de Paisagens do tipo Agreste). Elaborado pelos autores 
As faixas móveis remobilizadas ao sul e norte da área (FIGURA 5), delimitam superfícies de cimeira, com patamares topográficos que excedem os 900m de altitude. Estas fácies paisagísticas são assinaladas como "Brejos", onde a correlação entre a maior elevação e a penetração de umidade trazida pelos ventos alísios de SE favoreceu o aprofundamento do intemperismo, que coadunado à mineralogia das rochas metamórficas resultou no desenvolvimento de solos profundos; por vezes com mais de uma dezena de metros e alguma semelhança àqueles desenvolvidos nas zonas mais rebaixadas e próximas ao oceano. Entretanto, a variação térmica presente neste contexto ajudou a desenvolver uma vegetação mais próxima a dos ambientes séquitos das faixas centrais do Brasil. São comuns Anacardium occidentale (Cajueiro), de origem nativa, prosopis juliflora (Algaroba), Eucalyptus Regnans (Eucalipto) e Cupressus sempervirens (cipreste italiano), sendo estes últimos, indivíduos exóticos introduzidos na região, graças à sua adaptação ao inverno ameno e a pouca precipitação verificada na área. 0 mesmo pode se dizer das faixas metamórficas que resultam em relevo em cristas em variados estágios de dissecação.

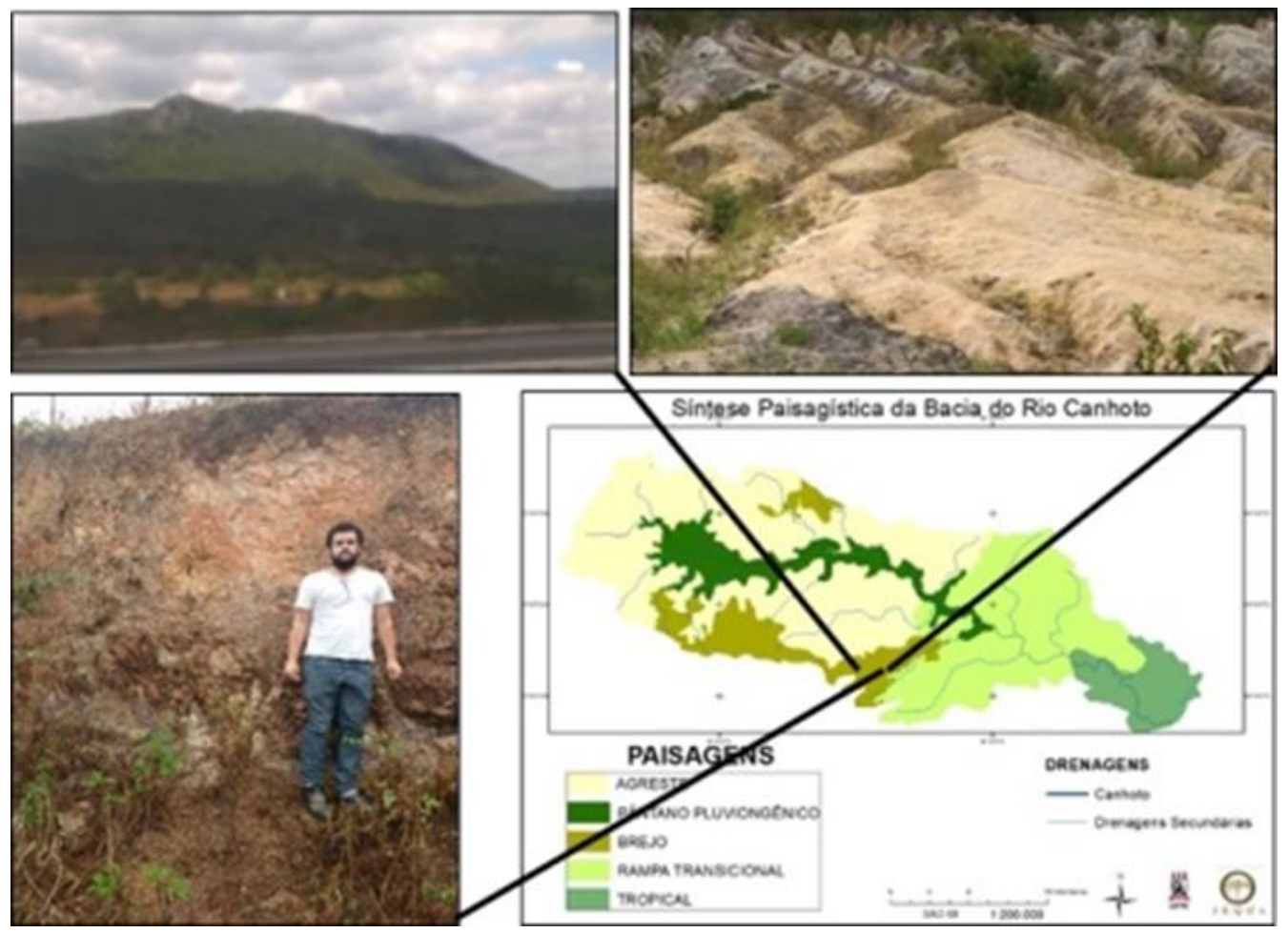

Figura 5. Compartimento de paisagens do tipo Brejo Fonte: Elaborado pelos autores.

Nestas áreas, o clima mais úmido favoreceu a formação de cabeceiras de drenagem e, em consórcio com os mantos de alteração mais espessos, a erosão linear tem favorecido a dissecação das superfícies de 
cimeira. As altas declividades não favorecem os usos agrícolas dificultando a apropriação do espaço para fins agropecuários, em função disso, se preservam áreas de vegetação secundária do tipo caatinga e Floresta Ombrófita ou Mata Atlântica, dependendo dos totais anuais de precipitação de cada setor.

Os sítios classificados como "pedimento pouco ondulado" (FIGURA 6) são passíveis apresentarem de estagnação de água nos períodos mais úmidos. Os fundos de vale, neste setor, ficam inundados na estação chuvosa e possibilitam o acúmulo de água que favorece o uso pelas populações locais. Estes pequenos pântanos sazonais permitem a formação de uma vegetação de pequeno à médio porte onde há presença de Prosopis, bem como a existênciaa de superfícies aráveis onde são cultivados, normalmente, Zea Mays (milho), Phaseolus vulgaris (feijão comum, também chamado, “carioca”) Vigna unguiculata, também chamado de feijão de corda, e o Cajanus cajan, conhecido no Nordeste como "andu"; variedade menos comum na região.

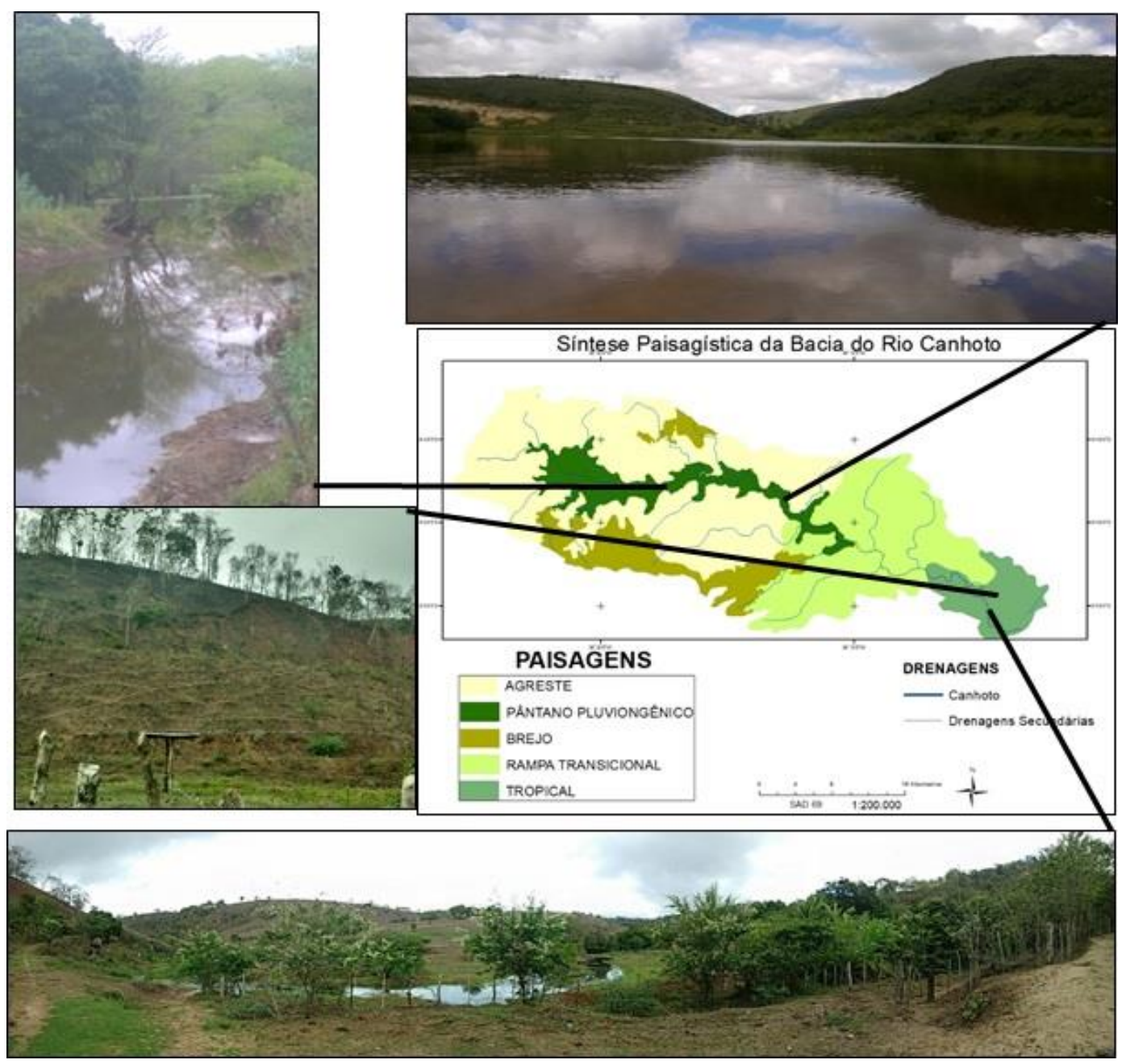

Figura 3. Compartimentos de paisagens do tipo Pântano pluviogênico e Tropical Elaborado por AUTOR 
A cobertura por manto de intemperismo e sedimentos remobilizados será tão mais evidente quanto for a exposição da superfície à umidade; neste caso, as faixas onde esta relação fica estabelecida estão também associadas à uma orientação das vertentes de direção NE-SO, transversal à direção dos alísios. A maior espessura da alterita resulta em trechos de relevo ondulado com dissecação fluvial, e predomínio dos processos de rastejo sobre as encostas.

Nestas regiões há grande variedade de vegetação arbórea com presença de exemplares da família Musaceae (Bananeira), Mangifera indica (Mangueira), originárias do sudeste asiático. Ocorrem ainda, Psidium guajava (Goiabeira) de origem na américa do Sul e Cocos nucifera (coqueiros) bem como outros membros da família Arecaceae (Palmeiras) de origem não esclarecida. Pela característica de maior umidade e temperatura, estas paisagens contam com solos mais profundos e presença latente de Floresta Ombrófila Aberta (BRASIL, 2009), como segunda vegetação de mata atlântica em estado de preservação ou uso pouco degradante. Ainda, são verificadas plantações de Sscharanum Officinarum (cana-de-açúcar), de origem exótica, este espécime foi introduzido na região no séc. XVI, por ocasião do início da colonização europeia no Brasil.

O relevo considerado "superfície inclinada" não conta com um predomínio fisionômico singular, de tal forma, que as características destas paisagens são marcadas pela presença de fragmentos de todos os cenários anteriormente descritos. De fato, estas paisagens podem ser classificadas como zonas de transição de microambientes (AB'SABER, 2003), definidos neste estudo como "rampa transicional". Estas áreas apresentam drenagens perenes, incluindo a do rio Canhoto. Situadas à uma altitude em torno dos $500 \mathrm{~m}$, estas áreas estão associadas a uma variação sazonal da umidade marcada por períodos de estiagem e precipitação. A paisagem apresenta gramíneas baixas nos pedimentos baixos e vales secos, segmentos preservados de Floresta Ombrófila Aberta junto às principais encostas, e, nas superfícies mais elevadas à NO, resquícios de indivíduos de caatinga (segunda vegetação), caracterizando, ao longo do seu transecto, um cenário síntese de todos os ambientes verificados na bacia, com exceção àqueles relacionados aos patamares topográficos mais elevados. 


\section{CONCLUSÕES}

A teoria do geossistema tem se revelado, ao longo de todo o século XX e XXI, capaz de contemplar as análises espaciais, no âmbito da geografia física, de maneira bastante eficaz, sobremaneira aquelas voltadas à compartimentação com ênfase geomorfológica. A proposta metodológica aplicada nesse contexto, para a modelagem cartográfica geossistêmica se revelou numa ferramenta importante no tocante à cartografia de paisagens no Nordeste oriental brasileiro, sobretudo no contexto das encostas orientais do Planalto da Borborema e superfícies de cimeira adjacentes.

Neste trabalho foram verificadas, pelo menos, 5 tipologias paisagísticas diferentes com base na sobreposição de seus respectivos arranjos ambientais que compreendem mecanismos particulares de dinamismo, bem como agrupamentos fisionômicos decorrentes dessa dinâmica, de maneira também particular, gerando composições espaciais singulares. Além disso, foram identificadas combinações ambientais pontuais, que configuram espaços físico-naturais de exceção em diversos graus de transformação antrópica. Esses refletem, numa perspectiva regional, o papel da variação de controles dos mecanismos dinâmicos agindo sinergicamente sobre as paisagens, e definindo configurações espaciais próprias.

A metodologia proposta assegura uma técnica integradora de modelagem cartográfica, voltada à análise das paisagens, tendo contumaz aplicação quando da análise ambiental, podendo representar uma ferramenta empregada tanto aos estudos ambientais, quanto àqueles que necessitam de lançar mão da compartimentação da paisagem para diversos fins, tal como é o caso da geomorfologia.

\section{AGRADECIMENTOS}

Ao Conselho Nacional de Desenvolvimento Científico e Tecnológico - CNPq

\section{REFERÊNCIAS}

AB’SÁBER, A. N. 2003. Os Domínios de Natureza no Brasil. Ed. Ateliê Editorial, São Paulo-SP. 
AZAMBUJA, R. N. Análise Geomorfológica em áreas de expansão urbana no município de Garanhuns - PE. Dissertação de Mestrado. UFPE, Recife, 2007.

BESSE, J. Ver a Terra: Seis ensaios sobre a paisagem e a geografia. Ed. Perspectiva, São Paulo. 2000.

BRASIL. Florestas do Brasil em Resumo. Ministérios do Meio Ambiente, Serviço Florestal Brasileiro. Brasília - DF, 2009, $124 \mathrm{p}$.

CAVALCANTI, L.C.S.; CORREA, A.C.B; Geossistemas e Geografia no Brasil. Revista Brasileira de Geografia, v.61, n. 2, Rio de Janeiro-RJ, 2016.

CAVALCANTI, L.C.S. Cartografia de paisagens: fundamentos. Sao Paulo: Oficina de textos. 2014. 96 p.

CAVAlCAnTI, L. C. S. Da Descrição de Áreas à Teoria dos Geossistemas: uma Abordagem Epistemológica sobre Sínteses Naturalistas. Tese (Doutorado em Geografia). Recife: UFPE. 2013. $217 \mathrm{f}$.

CAVALCANTI, L. C. S. Geossistemas do Estado de Alagoas: uma contribuição aos estudos da natureza em geografia. Dissertacao (Mestrado em Geografia). Recife: UFPE. 2010. 132f.

CORRÊAA, A. C. B. Dinâmica geomorfológica dos compartimentos elevados do Planalto da Borborema, Nordeste do Brasil. Rio Claro. Tese de Doutorado - IGCE, UNESP. 2001. f386.

CORREA, A.C.B. O geossistema como modelo para a compreensão das mudanças ambientais pretéritas: uma proposta de geografia física como ciência histórica. In: Sá, A.J. \& CORREA, A.C.B. Regionalização e análise regional. Perspectivas e abordagens contemporâneas. Recife: Editora Universitária da Universidade Federal de Pernambuco, 2007, p. 33-45.

CORREA, A.C.B.; TAVARES, B. A. C.; MONTEIRO, K. A.; CAVAlCANTI, L. C. S.; LIRA, D. R. 2010. Megageomorfologia e Morfoestrutura do Planalto da Borborema. Revista do Instituto Geológico, São Paulo, SP, V. 31(1/2). p. $35-52$.

CHRISTOFOLETTI, A.Geomorfologia. São Paulo Ed. Edgard Blucher, 1980.

CHRistofoletTi, A. Modelagem dos Sistemas Ambientais. São Paulo Ed. Edgard Blucher, 1999.

DEMEK, J. Manual of Detailed Geomorphological Mappinq. Prague: Academia,1972. 520 p.

ISACHENKO, A.G. Landscape Science and Physical-Geographic Regionalization. Moscou: Vyshaya Shkola. 1991.

LIMA, E. M. Evolução Paleoambiental do Município de Garanhuns-PE, a partir de Análises Sedimentológicas: Aplicação do Método de Luminescência Opticamente Estimulada - LOE. Universidade Federal de Pernambuco - UFPE, Dissertação de Mestrado, 2014, 105p.

MOLION, L. C. B.; BERNARDO, S. O. Uma Revisão da Dinâmica das Chuvas no Nordeste Brasileiro. Revista Brasileira de Meteorologia, v. 17, n. 1, p 1-10, 2002

MONTEIRO, C.A.F. Análise rítmica em climatologia: problemas da atualidade climática de São Paulo e achegas para um programa de trabalho. São Paulo: Universidade de São Paulo, Instituto de Geografia, 1971, Climatologia, 1.

MONTEIRO, C.A.F. Derivações antropogênicas dos geossistêmas terrestres no Brasil e alterações climáticas: Perspectivas agrárias e urbanas ao problema da elaboração de modelos de avaliação. Simpósio Sobre a Comunidade Vegetal, como Unidade Biológica, Turística e Econômica. São Paulo, ACIESP, 1978. 
SILVA, C. A. da; FILHO, A. P. Geografia, Turismo e Análise Sistêmica. In: Contribuições à História e a Epistemologia da Geografia Física. Rio de Janeiro, RJ. Ed. Bertrand Brasil, 2006.

SOCHAVA, V.B. Algumas noções e termos da Geografia Fisica. Relatórios do instituto de Geografia da Sibéria e do Extremo Oriente. 3. 1963. p.53.

SOCHAVA, V.B. O estudo de geossistemas. Métodos em questão, n.16, IGUSP. Sao Paulo, 1977. 51 p.

SOLNTCEV, N.A. What is the difference between facies and biogeocenosis. Series Geography. n.2. 1967. (Em russo). Disponivel em: < http://www.landscape.edu.ru/book/book_solncev_2001_184.shtml> acesso em 12 fev 2018.

TRICART, J.F.L. Ecodinâmica. Rio de Janeiro, FIBGE/SUPREN. 1977. 91p.

TRICART, J.F.L.; CAILlEUX, A. Le problème de la classification des faits géomorphologiques. Annales de Géographie. t.65, n.349, 1956, p.162-186. 